although neutropenia was more frequent with sarilumab. Safety of sarilumab was generally comparable in monotherapy and combination studies; monotherapy was associated with fewer ALT elevations $>3 \times$ ULN compared with combination therapy: MONARCH, 3\%; MOBILITY, $8 \%$; TARGET, $4 \%$.

Conclusions: Sarilumab $200 \mathrm{mg}$ q2w + csDMARDs significantly reduced disease activity and improved physical function to a similar extent regardless of population (MTX-IR or TNF-IR) and as monotherapy. Safety profile of sarilumab was generally comparable across all 3 trials, with monotherapy resulting in fewer ALT elevations. Acknowledgements: This study was sponsored by Sanofi Genzyme and Regeneron Pharmaceuticals, Inc. Editorial assistance was provided by MedThink SciCom and funded by Sanofi Genzyme and Regeneron Pharmaceuticals, Inc. Disclosure of Interest: M. Genovese Grant/research support from: Roche, Sanofi, GlaxoSmithKline, R-Pharma, RuiYi, and Bristol-Myers Squibb, Consultant for: Roche, Sanofi, GlaxoSmithKline, R-Pharma, RuiYi, and Bristol-Myers Squibb, R. Fleischmann Grant/research support from: AbbVie, Amgen, Ardea, AstraZeneca, Bristol-Myers Squibb, Celgene, GlaxoSmithKline, Janssen, Eli Lilly, Merck, Pfizer, Roche, Sanofi, and UCB, Consultant for: AbbVie, Akros, Amgen, AstraZeneca, Bristol-Myers Squibb, Janssen, Eli Lilly, Pfizer, Roche, and UCB, H. van Hoogstraten Shareholder of: Sanofi Genzyme, Employee of: Sanofi Genzyme, E. Mangan Shareholder of: Regeneron Pharmaceuticals, Inc, Employee of: Regeneron Pharmaceuticals, Inc, S. Jayawardena Shareholder of: Sanofi Genzyme, Employee of: Sanofi Genzyme, G. Burmester Grant/research support from: AbbVie, Bristol-Myers Squibb, Medlmmune, Merck, Pfizer, Roche, and UCB, Consultant for: AbbVie, Bristol-Myers Squibb, Medlmmune, Merck, Pfizer, Roche, and UCB, Speakers bureau: AbbVie, Bristol-Myers Squibb, Merck, Pfizer, Roche, and $U C B$

DOI: 10.1136/annrheumdis-2017-eular.1275

\section{SAT0181 LOW DOSE INTERLEUKIN-2 COMBINED WITH TOCILIZUMAB SELECTIVELY INCREASES REGULATORY T CELLS HELPING REFRACTORY RHEUMATOID ARTHRITIS PATIENTS ACHIEVE REMISSION MORE RAPIDLY}

Z. Sheng-Xiao ${ }^{1}$, M. Xiao-Wen ${ }^{2}$, L. Xiao-Qing ${ }^{1}$, M. Miao ${ }^{1}$, W. Xiao-Yan ${ }^{1}$, N. Hong-Qing ${ }^{2}$, W. Cai-Hong ${ }^{2}$, L. Xiao-Feng ${ }^{1} .{ }^{1}$ Rheumatology; ${ }^{2}$ The Second Hospital of Shanxi Medical University, Taiyuan, China

Background: Rheumatoid arthritis (RA) is a prevalent chronic autoimmune inflammatory disease. Its pathogenesis is closely associated with a failure of endogenous immune tolerance that caused by the imbalance of pro-inflammatory T helper 17 (Th17) cells and anti-inflammatory regulatory T (Treg) cells. Lowdose Interleukin-2 (IL-2) has been showed to induce both Th17 and Treg cells' expansion and activation while IL-6 antagonist Tocilizumab suppresses the differentiation of Th17, which is expected to control the development of RA.

Objectives: To study the influence of the combination of IL-2 and Tocilizumab on $T$ cells subgroups and its clinical efficacy and safety on refractory RA.

Methods: Total 50 RA patients with low Treg cells, who had been treated with glucocorticoids and DMARDs for over 6 months, were divided into three groups randomly. Patients in non-IL-2 group $(n=15)$ were still given conventional glucocorticoids and DMARDs. Patients in IL-2 group $(n=26)$ were not only given those treatments, but injected subcutaneously human IL-2 (aldesleukin) at 50 WIU per day for a 5 day course. Patients in IL-2 and Tocilizumab group $(n=9)$ were not only received the treatment like IL-2 group, but also treated with Tocilizumab at the dosage of $160 \mathrm{mg}$ during the day 1 and day 3 . The demographic features, clinical manifestations and laboratory indicators were compared before and after the treatment.

Results: There was no difference among all groups in gender, age and course of the disease $(p>0.05)$. The ratios of Th1/Th2 and Th17/Treg were significant correlated with ESR, the number of tender or swollen joints and DAS28-ESR $(p<0.05)$ in all three groups of patients. After treatment, the number of Th17 cells and Treg cells was significantly increased in IL-2 group $(p<0.01)$. In IL-2/Tocilizumab group after the treatment, the number of Treg cells were also significantly increased $(p<0.05)$, but not the Th17 cells $(p>0.05)$, leading to a quickly decrease in their ratio $(p<0.05)$. Before the treatment, there was no difference in clinical manifestations among all three groups $(p>0.05)$, but compared with non-IL-2 group, there was a significantly decrease in the number of tender joints $(p<0.01)$ or swollen joints $(p<0.05)$ and DAS28-ESR $(p<0.01)$ in IL-2 group and IL-2/Tocilizumab group after the treatment. Patients in IL-2/ Tocilizumab group had better clinical manifestations' remission although no significant difference compared with IL-2 group $(p>0.05)$. There was no difference in blood routine, liver and renal functions both before and after the treatment among all groups $(p>0.05)$.

Conclusions: IL-2 can effectively increase the level of Treg cells as well as that of Th17 to some degree; while IL-2 combined with Tocilizumab only effectively expand Treg cell number without Th17 increasing, thereby quickly recovers the balance of Th17 and Treg cells. This combination selectively stimulate Treg Cells leading to induce autoimmune tolerance, and seems to help RA patients achieve remission in a rapid way without over-treatment and evaluated side effect, though the long term benefits of this therapy are required to further study in more patients. Acknowledgements: The authors thank Chong Gao for the assistance.

Disclosure of Interest: None declared

DOI: 10.1136/annrheumdis-2017-eular.3611

\section{SAT0182 SIRUKUMAB LEADS TO SIGNIFICANT AND CLINICALLY MEANINGFUL IMPROVEMENTS IN HEALTH-RELATED QUALITY OF LIFE THAT MEET OR EXCEED NORMATIVE VALUES IN PATIENTS WITH RHEUMATOID ARTHRITIS REFRACTORY TO TNF INHIBITORS IN POST HOC ANALYSES OF A PHASE 3 TRIAL}

V. Strand ${ }^{1}$, R. Ganguly ${ }^{2}, \mathrm{~N} . \mathrm{Li}^{3}, \mathrm{~K}$. McQuarrie ${ }^{3} .{ }^{1}$ Stanford University, Palo Alto, $C A ;{ }^{2}$ GlaxoSmithKline, Collegeville, PA; ${ }^{3}$ Janssen Research \& Development, LLC, Spring House, PA, United States

Background: Patients (pts) with rheumatoid arthritis (RA) experience reduced health-related quality of life (HRQoL). Sirukumab (SIR) is an anti-interleukin-6 (IL-6) monoclonal antibody.

Objectives: These post hoc analyses evaluated improvements over time in HRQoL relative to an age/gender-matched normative population in RA pts with inadequate responses to tumor necrosis factor inhibitors (TNF-IR) from the phase 3 SIRROUND-T trial.

Methods: 878 pts received SIR 50mg every 4 weeks (q4w), SIR 100mg every 2 weeks (q2w), or placebo (pbo) q2w. Health-related physical/emotional wellbeing were measured at baseline (BL) and Wk 24 by the 36-item Short Form Questionnaire (SF-36), fatigue by Functional Assessment of Chronic Illness Therapy (FACIT)-Fatigue (FACIT-F), and physical function by Health Assessment Questionnaire-Disability Index (HAQ-DI).

Results: SF-36 physical and mental component summary (PCS and MCS) mean scores at BL for pbo, SIR $50 \mathrm{mg} \mathrm{q} 4 \mathrm{w}$, and $100 \mathrm{mg}$ q2w indicated substantial impairment (PCS: 33.2, 31.8, and 32.4; MCS: 41.9, 41.2, and 42.1). Significantly greater improvements from BL were reported at Wk 24 with SIR $50 \mathrm{mg} \mathrm{q} 4 \mathrm{w}$ and $100 \mathrm{mg}$ q $2 \mathrm{w}$ vs pbo in PCS (4.8 and 5.1 vs 1.7$)$ and MCS (3.9 and 4.0 vs 1.1) mean scores (all $P<0.001$ ), exceeding the minimum clinically important difference (MCID) of 2.5. Significantly greater least squares mean changes in the 8 SF-36 domain raw scores were reported with both doses of SIR vs pbo at Wk 24; all were $>$ MCID of 5.0 (Table; Figure). More pts receiving SIR $50 \mathrm{mg} \mathrm{q4w}$ or $100 \mathrm{mg}$ q2w reported SF-36 domain scores $\geq$ normative values (ranges: $11-34 \%$ and $13-42 \%$ ) vs pbo (range: 6-29\%). For pbo, SIR 50mg q4w, and SIR 100mg q2w, BL FACIT-F scores were $26.0,24.2$, and 25.2 ; clinically meaningful improvements $>$ MCID (4 points) were reported by 54.3 and $51.4 \%$ of pts receiving SIR $50 \mathrm{mg} \mathrm{q} 4 \mathrm{w}$ and $100 \mathrm{mg}$ q2w vs $33.7 \%$ with pbo $(P<0.001)$. Numerically greater percentages of pts reported scores $\geq$ normative values with both doses of SIR vs pbo (27 and $28 \%$ vs $16 \%$ ). BL HAQ-DI scores were $1.57,1.65$, and 1.61 with pbo, SIR $50 \mathrm{mg}$ $\mathrm{q} 4 \mathrm{w}$, and $100 \mathrm{mg} \mathrm{q} 2 \mathrm{w}$. Clinically meaningful improvements (change of $\leq-0.22$ ) were reported by significantly higher proportions of pts receiving SIR $50 \mathrm{mg} q 4 \mathrm{w}$ $(52.2 \%)$ or $100 \mathrm{mg} \mathrm{q2w}(54.8 \%)$ vs pbo $(37.4 \% ; P<0.001)$. Numerically more pts reported HAQ-DI scores $\geq$ normative values with SIR $50 \mathrm{mg} \mathrm{q4W}$ and $100 \mathrm{mg}$ q2W vs pbo ( 13 and $16 \%$ vs $9 \%$ ).

Table 1. Improvements in SF-36 Domain Scores at Wk 24 (all $P<0.001$ )

\begin{tabular}{lccc}
\hline Domain & LSM change SIR 50mg q4w & LSM change SIR $100 \mathrm{mg}$ q2w & LSM change pbo \\
\hline Physical function & 9.38 & 10.75 & 0.47 \\
Role-physical & 12.85 & 13.52 & 5.03 \\
Bodily pain & 17.66 & 17.51 & 7.46 \\
General health & 6.81 & 7.76 & 1.57 \\
Vitality & 10.10 & 9.68 & 4.14 \\
Social function & 12.40 & 11.75 & 3.68 \\
Role-emotional & 9.29 & 9.86 & 0.42 \\
Mental health & 6.73 & 7.96 & 2.10 \\
\hline
\end{tabular}

LSM, least squares mean.

Figure. SF-36 domains at Wk 24 for SIR 50mg $q 4 w$ and SIR $100 \mathrm{mg} q 2 w$

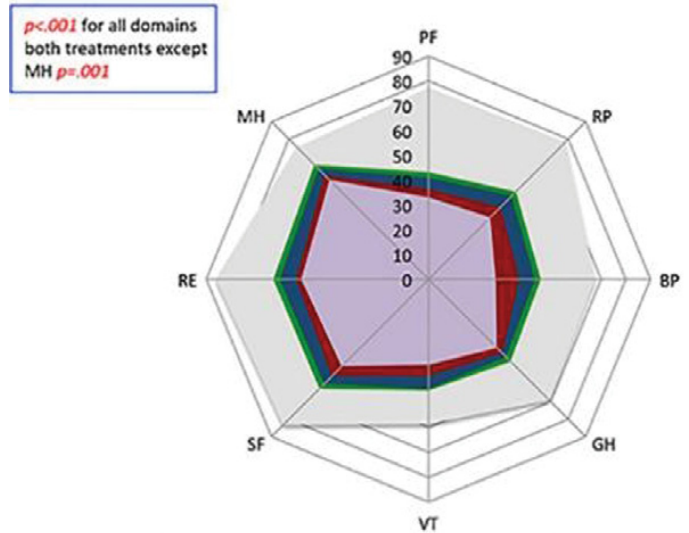

AVG Norms 3003 = S1R $100 \mathrm{mg}$ q 2W -WK24 a S1R S0mg q4W -WK24 = Placebo - WK24 = Combined Baseline

Conclusions: In TNF-IR RA pts, SIR treatment resulted in greater and clinically meaningful improvements in HRQoL vs pbo that met or exceeded population normative values, with similar results for SIR $50 \mathrm{mg} \mathrm{q} 4 \mathrm{w}$ and $100 \mathrm{mg}$ q2w. Disclosure of Interest: V. Strand Consultant for: Abbvie, Amgen, AstraZeneca, Biogenldec, Boehringer Ingelheim, Celltrion, Crescendo, Genentech/Roche, GSK, 